Childrens' report pattern from witnessing homicidal violence - the effect of repeated experience and repeated interviews

Azade Azad

Master thesis $30 \mathrm{hp}$

Department of Psychology

Supervisors: Sven Å. Christianson and Elisabeth Borg May 2011

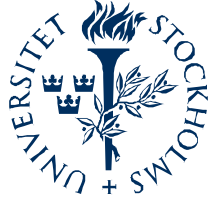

Stockholms universitet 


\title{
CHILDRENS' REPORT PATTERN FROM WITNESSING HOMICIDAL VIOLENCE - THE EFFECTS OF REPEATED EXPERIENCE AND REPEATED INTERVIEWS
}

\author{
Azade Azad
}

\begin{abstract}
The aim of the present study was to examine childrens' report pattern after witnessing homicidal violence and whether witnessing repeated violence have an effect on the childrens' report. In addition, the aim was also to study whether repeated interviews with the child leads to a more detailed report. The results revealed that the majority of the children reported a great amount of details about what happened before, during, and after the homicide in the police interviews, where most of the children provided great amount of details concerning sensitive information (i.e., severe and critical information) about the violence. Witnessing repeated violence did not significantly affect the amount of details given. Repeated interviews did not affect the amount of details provided. These findings, which add important information to research on childrens' memory of violence, are discussed in detail.
\end{abstract}

According to prevalence estimates, large numbers of children are exposed to different forms of violence each year where some children are directly victimized and abused themselves while others become bystander witnesses. The different types of violence children are exposed to differ and vary from less severe forms of battery to the most extreme forms such as homicide (Fowler, Tompsett, Braciszewski, Jacques-Tiura, \& Baltes, 2009). Some children encounter violence once and in a single setting, whereas others are exposed to repeated violence in multiple contexts (Finkelhor, Ormrod \& Turner, 2007), such as in their neighborhoods and communities (Fowler, et al., 2009; Weist, Acosta \& Youngstrom, 2001), in their schools (Janosz, Archambault, Pagani, Pascal, Morin \& Bowen, 2008) and in their homes (Burman \& Allen-Meares, 1994; Edleson, 1999; Överlien, 2010).

\section{Childrens' memories and reports of traumatic and abusive events}

A vast number of studies have investigated the nature of childrens' memories of and recall for stressful events (for reviews see Christianson, 1992; Deffenbacher, Bornstein, Penrod \& McGorty, 2004). Research has repeatedly shown that children, even as young as three years old, have extensive memories for different types of stressful events (Howe, Courage \& Peterson, 1996) such as painful medical procedures (Goodman, Quas, Batterman-Faunce, Riddlesberger \& Kuhn, 1994, 1997), natural disasters (Bahrick, Parker, Fivush \& Levitt, 1998; Fivush, Sales, Goldberg, Bahrick \& Parker, 2004), physical and sexual abuse (Ghetti, Goodman, Eisen, Qin \& Davis, 2002, Leander, Christianson \& Granhag, 2007) and kidnapping (Terr, 1988).

Research regarding childrens' memories of violence exposure has mostly investigated childrens' experiences with domestic violence (Eriksson, Biller \& Balkmar, 2006; Eriksson, Källström Cater, Dahlkild-Öhman \& Näsman, 2008; Lyckner, 1997; Weinehall, 1997) and studies investigating childrens' memories and recall of being witnesses to homicidal violence are limited (Eth \& Pynoos, 1994; Pynoos \& Eth, 1984, 1985). The available research has shown somewhat inconsistent results. While some studies indicate that children who have witnessed violence have strong memories about the violence over time, especially in regard to 
central details of the event (Pynoos \& Eth, 1984; Steeves, Laughon, Parker \& Weierbach, 2007; Överlien \& Hydén, 2007) other studies indicate a tendency of forgetting (Follmer Greenhoot, McCloskey \& Glisky, 2005). One study showed for example that some children remembered less information about the violence over time and in their recollection excluded some details about the severe violence (Follmer Greenhoot et al., 2005). The vast majority of studies however indicate that children do not show oblivion due to trauma, instead they are well aware of their experiences and can differentiate real experiences from fantasies.

Children who have been interviewed after having witnessed the murder of a parent do not show any tendencies to misbelieve what they have witnessed and are well aware of that what they experienced happened for real (Pynoos \& Eth, 1985). A previous study investigating childrens' memories and reports of homicidal violence revealed that children remember their experiences well (Christianson, Azad, Leander \& Selenius, manuscript in preparation), a result that is line with previous research on childrens' memories of stressful events (Christianson, 1992; Goodman, Hirschman, Hepps \& Rudy, 1991; Terr, 1988). In contrast to other victimized children (e.g., sexually abused children) children who had witnessed homicidal violence did not show the same reluctance to report about the severe violence they have witnessed as do sexually abused children about the sexual abuse (Leander, Granhag \& Christianson, 2005; Sjöberg \& Lindblad, 2002; Svedin \& Back, 2003). The majority of the children provided great amount of details concerning sensitive information (i.e., severe and critical information) about the violence. Other studies have shown that children, in addition to visual memories also have bodily and auditory memories, where auditory related memories have been shown to be perceived as extra agonizing (Överlien \& Hydén, 2007). Childrens' memories, if not always verbally expressed, have appeared in other various forms, such as in the child's play, where for example a child who witnessed the killing of her mother re-enacted the fatal event in plays (Strati, 2010). The experiences can also appear as fantasies or in the childrens' dreams (Pynoos \& Eth, 1985). Taken together, children who have been exposed to serious forms of violence seem to have the ability to remember the traumatic events, and express their memories in different ways.

\section{Repeated violence}

Deadly violence is, more often than not, perpetrated by someone closely related to the victim (e.g., a family member, relative or friend), where a high number of these cases involve intimate partner femicides, which is the murder or attempted murder of a women by a close partner such as a boyfriend, husband, ex-partner etc. (Brå, 2008; Brå, 2007). In the vast majority of intimate partner femicides, the woman has been battered for a long period of time, sometimes several years, before she is killed, subjecting the children to the trauma of witnessing severe violence even before the homicidal event (Smith, Morroco \& Butts, 1998). Research has shown that if a person experiences an event of similar character repeatedly there is an increased likelihood that he or she will create a schematic memory of the events (Hintzman, 1986; Hudson, Fivush \& Kuebli, 1992; Schank, \& Abelson, 1977). Schemas are abstract knowledge structures that reflect the understanding of the temporal and/or causal sequence of events that typically occur in specific contexts (Farrar \& Goodman, 1992). When reporting about schematic memories the report can sometimes be undetailed and fragmentary (Hintzman, 1986). Previous studies have shown that children who have experienced a familiar event numerous times can form "scripts" of the events where even children as young as three years of age have been shown to be able to create schematic memories (Farrar \& Goodman, 1992). In comparison to children who only experienced an event once, children who have had repeated experiences have been shown to recall more general information (Hudson, 1990). They typically enhance recall of features common to all episodes, making it difficult to 
retrieve details associated with the specific event which leads to fragmentary statements lacking details describing the episode (Roberts \& Powell, 2001). They are however correct in the information they report and are sometimes, more accurate in their recall compared to children who only experienced the event on one occasion. They have also been shown to be more resistant to external intrusion errors and false-suggestion exemplifications (Powell, Roberts, Ceci \& Hembrooke, 1999).

Children who have suffered more severe and long-lasting abuse may develop different defense and coping-strategies to protect themselves from these experiences (Svedin \& Back, 2003; Terr, 1991). In some cases a dissociative reaction and behavior can occur (Putnam, 1997). Dissociation is a psychological mechanism operating during and immediately after the traumatic event, with the purpose to act as a coping strategy during extreme stress and trauma. The child can, for example, change focus by consciously directing his or her attention and awareness to his or her thoughts and imagination, instead of the occurring violence. The idea is that dissociation results in isolated features of the traumatic events that are not integrated into other memory features, which has a negative affect on the encoding of information and may negatively affect the reporting and lead to fragmentary recall (Putnam, 1997). However, the different pattern has also been suggested, where dissociation among maltreated children has been associated with more details reported (Eisen, Qin, Goodman \& Davis, 2002). This could perhaps be due to dissociations of feelings rather than facts, where the child uses emotional regulation, instead of cognitive avoidance, to handle the occurring violence. Research has also shown that children who have been exposed to long-lasting abuse are less likely to disclose the abuse than children who have been exposed to few acts of less severe abuse (Arata, 1994; Hershkowitz, Lanes \& Lamb, 2007), even if contradictory findings showing the opposite pattern have also been reported (London, Bruck, Ceci \& Shuman, 2007). Repeated experiences can thus have both, beneficial and detrimental effects on childrens' memory and reports and it is of interest to further investigate how witnessing repeated acts of violence affects the report of the event.

\section{Repeated interviews}

Repeated interviews are often necessary to establish rapport with the child in order to help him or her dare to report the abuse he or she has experienced, and time is often needed to enable such trust (Leander, 2010; Svedin \& Back, 2003). For example, one study has suggested that sexually abused children may need two or three interviews to report abuserelated information (Leander, 2010). Furthermore, several studies indicate that repeated interviewing increases accuracy, even when misleading questions are used (Goodman \& Quas, 2008) and that repeated interviews, when conducted correctly, can lead to more, and more correct, information reported (Hershkowitz \& Terner, 2007). Children who are interviewed more than once have also been shown to be less likely to deny and omit information in the subsequent interviews in comparison to the first (Leander, 2010). Thus, when children are given a second chance to provide information about what they have witnessed, they can further elaborate the information that they report and even provide entirely new information about their experiences.

There is however a divided opinion on whether repeated interviews are beneficial, or have a detrimental effect on the outcome of an interview (La Rooy, Lamb \& Pipe, 2009; for a review on the subject, see La Rooy, Katz, Malloy \& Lamb, 2010). Some researchers emphasize that repeated interviews foster inaccurate recall and are inherently suggestive, while others highlight the benefits of allowing witnesses more than one opportunity to recall information. Most professional guidelines discourage repeated interviews with child witnesses and victims 
of crimes. In Sweden, it is for example prohibited to conduct more investigative interviews with children than is absolutely necessary in view of the nature of the investigation and out of respect for the child's well being (17§ FUK "the Pre-trial Order"). The common assumption is that repeated interviews are intrinsically suggestive, have negative consequences for the accuracy of the report, produce inconsistency in the witness testimony and recollection of the event and that they may cause the witness or victim additional distress (Goodman \& Quas, 2008). Research has, as pointed out above, however shown that repeated interviews often are necessary and beneficial for the outcome of the interview.

\section{The present study}

The aim of the present study was to examine childrens' report pattern about being witnesses to homicidal violence and whether witnessing repeated violence has an effect on childrens' reports, by comparing the testimonies of children who have been witness to a single act of violence with children who have been exposed to repeated violence. In addition, the aim was to study whether repeated interviews with the child leads to more details reported. It was predicted that repeated interviewing would lead to more details reported by the childwitnesses. Due to the paucity of previous research and the diverse findings, about how witnessing repeated violence affect childrens' memories and reports, no further predictions were made.

\section{Method}

\section{Material}

The data for the present study were retrieved in 2010 from 14 different Swedish criminal investigation departments scattered across the country (Gotland, Kronoberg, Jämtland, Kalmar, Norrbotten, Södermanland, Uppsala, Värmland, Västerbotten, Östergötland, Västmanland, Dalarna, Skåne, Västra Götaland). An enquiry was sent out to all of the criminal investigation departments in Sweden $(n=21)$ requesting access to investigations concerning homicide, manslaughter and battery with fatal outcome as well as attempted homicide and attempted manslaughter during January 2000 to June 2010. The material requested was the pre-investigation protocol including transcribed cross-examination records (from audio or video recorded interviews) with children who had witnessed (heard, seen or both heard and seen) homicidal violence, as well as various forms of verification data such as police interviews with other witnesses, the victim (if still alive), the perpetrator, pictures and other documentations of the victim, technical protocols and maps and sketches over the crime scene. All investigations available in the different departments, fitting the request, were sent, or collected from the above-mentioned criminal investigation departments, and reports with altogether 64 children were included in the present study. The reason for excluding some investigations was the lack of child interviews in the investigations, that the child had neither heard nor seen the deadly violence, the lack of a dialog interview with the child or that the child was older than 18 years old during the police interview.

\section{Participants}

The final sample consisted of 64 child interviews; 25 (39\%) boys and $39(61 \%)$ girls with ages ranging from 3 to 17 at the time of the police interview $(\mathrm{M}=10.3, \mathrm{SD}=3.6)$. On average, the children had been interviewed on 1 occasion (varying between 1 and 5 times). Twelve $(19 \%)$ children had been exposed to repeated acts of severe violence by the perpetrator against the victim, while $39(61 \%)$ children only witnessed one single act of deadly violence. Thirteen $(20 \%)$ children were coded as unclear, as it was unambiguous whether they had 
witnessed repeated violence or not, in other words it could not, on the basis of the information in the pre-investigation protocol, be determined if the child had witnessed one ore several acts of violence by the perpetrator against the victim. To the best of my knowledge, no specific interview guide was used. All personal and sensitive information (e.g., surname, personal identification number, address) were handled confidentially, and measures were taken to ensure that the individuals included in the present study could not be identified.

\section{Coding procedure}

To examine the amount and types of information the childrens' statement consisted of, a datadriven coding procedure was used. The coding scheme was designed based on the interpretation of the material, as well as the research questions that were wished to be answered. The different coding categories were also based on previous research on childrens' memory and report (e.g., Leander, et al., 2005; Leander, et al., 2007). All of the childrens' interviews were coded separately and all informative details mentioned were counted and summarized individually. The following variables were coded in the present study: demographical and other information about the child and the offense (e.g., crime classification, age and gender of child, identification of victim and perpetrator, the relationship of the perpetrator and victim to the child, if the child had witnessed repeated violence, etc.); information about the homicidal violence per see (e.g., if the murder/attempted murder included knife violence, strangling, fire arms, choking etc.); information about the questioning with the child (e.g., place of interview, number of interviews, types of questions asked etc.); the child's reporting and the amount and different types of details provided by the child (e.g., details about what happened before the homicide, details about what happened after, details about severe and minor violence, details about the perpetrator and the victim etc.); amount of denial and withholding in the child's testimony ("denial" was coded when the child claimed something did not happen when in fact it did and "withholding" was coded when the child had an opportunity to report something but failed to do so) as well as claim of memory loss. When coding the amount of details provided by the children different categories were used: no details; few details; several details; many details; not applicable. No details, intended that the child provided no details at all concerning the specific type of information coded; few details intended one or two details; several details was coded when the child told three to five details and many details implied seven ore more details. Not applicable was coded when a type of detail could not be coded due to different reasons (for example if the victim was dead it would not be applicable to code what the child reported about the victims verbalization).

\section{Inter-rater reliability}

One rater coded all the interviews with the children. Reliability measures were taken by randomly selecting $20(30 \%)$ child interviews to be coded by a second independent rater. Intraclass correlation coefficient (ICC) statistics was performed to determine the consistency of the ratings by the two coders (Bartko, 1996). ICCs ranged from 0.53 to 0.95 (see Table 1). Disagreements were solved by discussion between the two raters. 
Table 1. Inter-rater reliabilities for the different categories.

\begin{tabular}{lc}
\hline Category & ICC \\
\hline Details before the homicide & .81 \\
Surrounding details & .53 \\
Emotional surrounding details & .80 \\
Details about minor assault & .88 \\
Details about severe assault & .85 \\
Details about the perpetrator's verbalization & .90 \\
Details about the perpetrator's emotions & .97 \\
Details about victim's reactions & .64 \\
Details about victim's injuries & .92 \\
Details about victim's verbalizations & .95 \\
Details about victim's emotions & .80 \\
Details about own acts & .93 \\
Details about own verbalizations & .92 \\
Details about own thoughts and feelings & .78 \\
Details after the homicide & .61 \\
\hline
\end{tabular}

Results

\section{Childrens' report pattern}

Most of the children reported a great number of details concerning different parts of the homicidal event in the police interviews, where $65.6 \%$ of the children provided several or many details about what happened before the homicide and $67.2 \%$ provided several or many details about what happened after. The majority of the children provided great numbers of details concerning sensitive information (i.e., severe and critical information) about the violence, where $53.2 \%$ reported several or many details about the severe assault (see Table 2). No significant difference in amount and type of details was found between boys and girls. The age of the children was, after a Bonferroni-correction, also nonsignificantly related with number of details given by the children in the police interrogations.

Few children omitted or withheld information. Three children withheld some details about the homicide systematically, two children withheld information in the beginning of the police interrogation and three children withheld information throughout the whole interview. Three children denied information about the homicidal violence (one child denied information initially and two children throughout the whole interview). Five children claimed that they had not heard or seen the homicidal violence. None of the children claimed loss of memory before or after the homicide, and the vast majority of the children did not state memory loss during the homicide. There was only one child who initially claimed memory loss during the homicide, whereas four children systematically claimed memory loss for some details during the homicide.

\section{Repeated violence}

In order to explore whether witnessing repeated violence had an affect on the amount of details reported, the children were divided into two groups. One group consisted of children who had witnessed a single act of deadly violence whereas the other group consisted of 


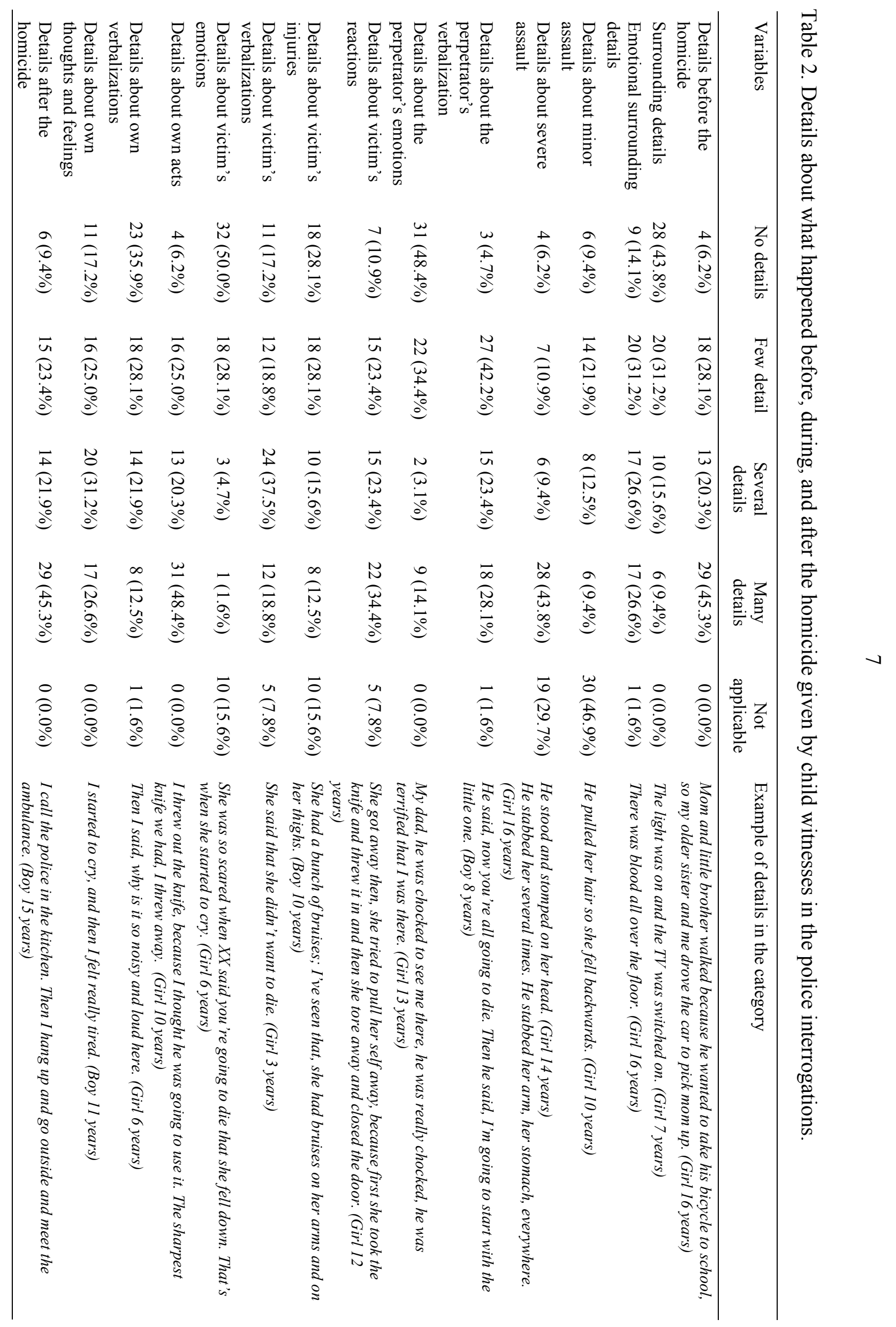


children who had witnessed several acts of violence. Amount of details given by these two groups of children were compared by using Mann-Whitney $U$ statistics, and the results, as can be seen in Table 3, showed that children who had witnessed repeated violence did not differ significantly compared to children who only witnessed a single act of violence. Chi-Square tests showed no significant difference in withholding, denial, claim to not have seen or heard the violent episode, or claim of memory loss with respect to if the children witnessed repeated or a single act of violence (see Table 3 ).

\section{Repeated interviews}

Moreover, I also wanted to investigate whether repeated questioning would have an impact on the amount of details reported by the children in the police interrogations. The children were divided into two groups; one group consisting of children who were interviewed once and the other consisted of children who had been interviewed twice or more times. Mann-Whitney $U$ statistics, revealed after a Bonferroni correction, that there were in general no significant differences between the two groups in numbers of details provided (see Table 4).

\section{Discussion}

The present study aimed at investigating the report pattern of children who had witnessed homicidal violence and to explore the possible effect repeated violence exposure and repeated questioning have on childrens' reports. Results revealed that the majority of the children provided detailed reports about the homicidal violence they had witnessed, including details of what happened before, during, and after the violent act, indicating that they have extensive memories of these experiences. Altogether, this is in line with previous research based on childrens' memory for stressful and traumatic events (Christianson, 1992; Pynoos \& Eth, 1985; Terr, 1988). Few children in the present study denied or withheld information, and almost no one claimed memory loss, a result that is dissimilar to the pattern of child sexual abuse victims, who tend to withhold information about the abuse (Leander, et al., 2005; Leander, et al., 2007; Svedin \& Back, 2003). Neither age nor gender seemed to affect amount and type of details that the children reported, indicating that children of all ages, even as young as three years old, can provide detailed reports about their experiences. The specific findings suggest that children who have had a single experience of deadly violence do not differ in their report pattern in comparison to children with repeated encounters of violence. Moreover, it was revealed that repeated questioning did not lead to more details reported. These findings, which add important information to research on childrens' memory of violence, are discussed in detail next.

As previous research has shown, repeated experiences of trauma can affect the memory and report of the event in different ways (i.e., the formation of schematic memories, or use of dissociation, e.g., cognitive avoidance and emotional regulation, which both can impair and enhance memory). Given the data in the present study, it cannot be confirmed or outruled that the childrens' memory were affected by these factors. The present results showed merely that there were no differences in the report patterns of the children, whether they had witnessed a single violent episode or repeated violence, suggesting that experiencing repeated violence does not origin these types of mechanisms. One possible explanation, as to why repeated violence exposure did not have an effect on the childrens' memories and report, could be that the act of violence they were interviewed about differed from the previous act of violence 


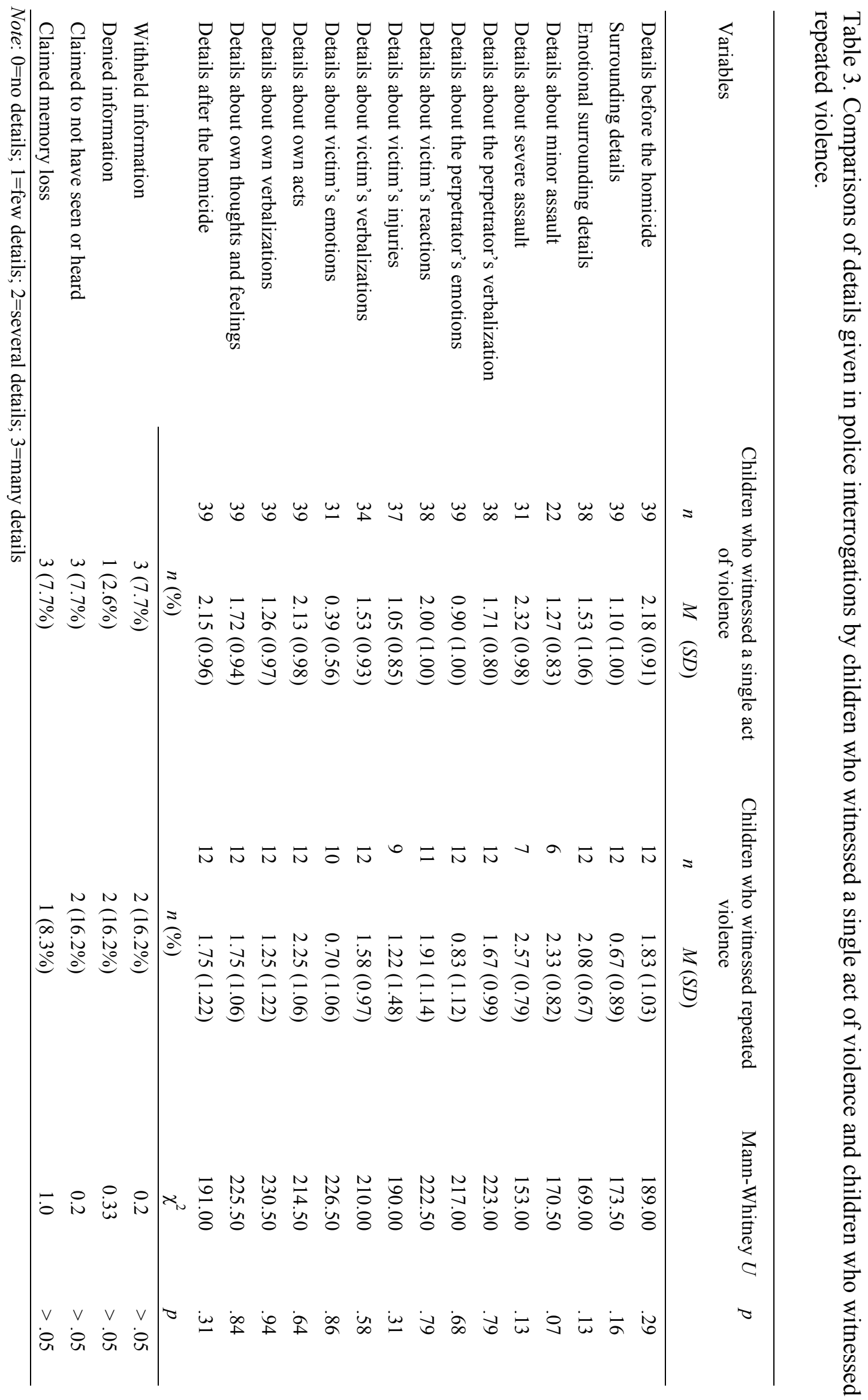




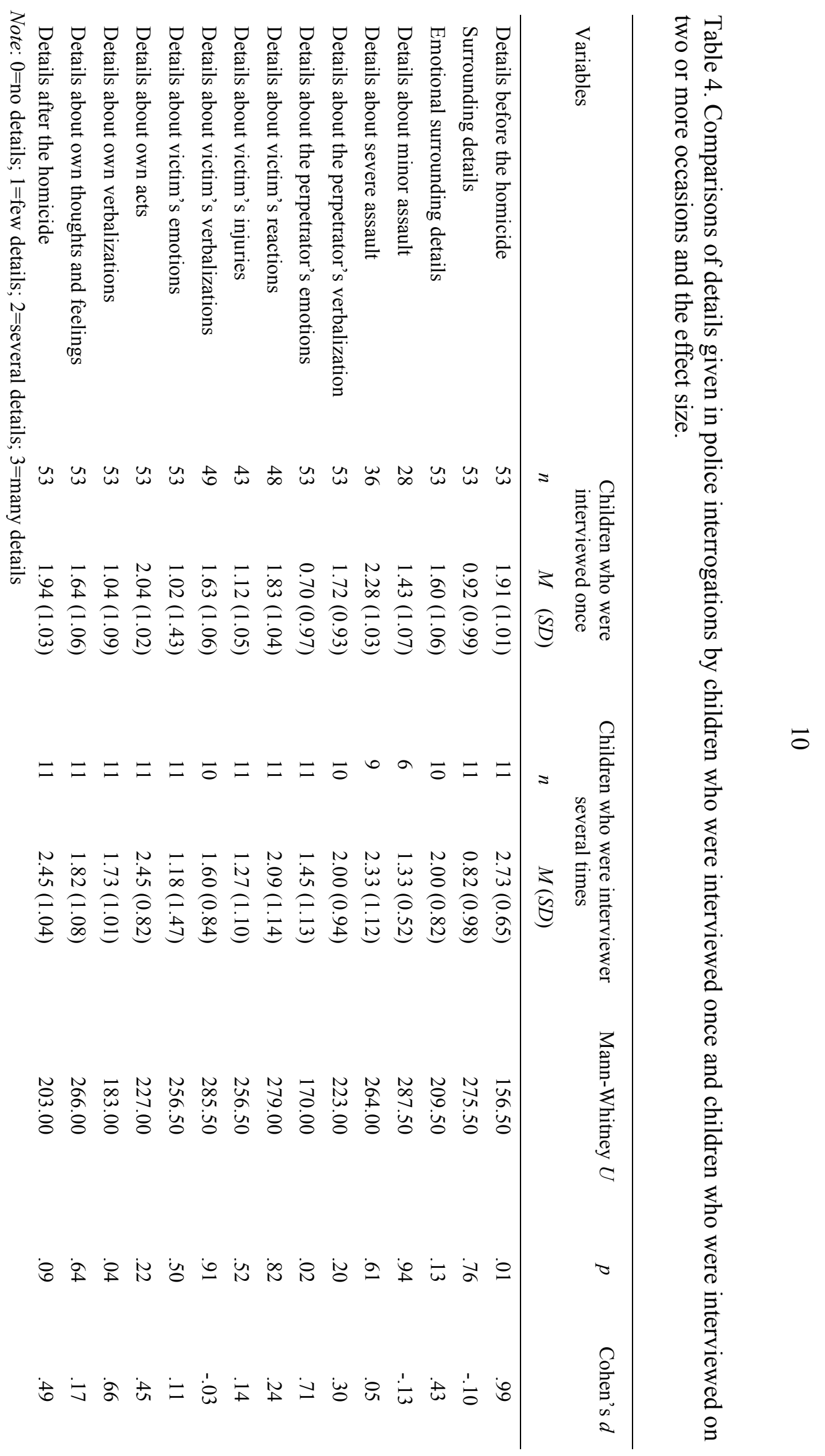


they had witnessed, in the sense that this event was more violent and brutal, and deviated from the previous experiences of violence. It could also be due to errors in the coding of the data. A large group of the children $(n=13)$ could not be categorized into any of the two groups, due to ambiguous information in the investigation-protocol, which could have affected the results. In the same way, and due to the nature of the material used to categorize the children (i.e., the pre-investigating protocol), it is possible that some children were wrongly categorized, as to belonging to the single group when in fact they could have witnessed repeated violence, which also could have affected the results. These results do however show that children who have had repeated experiences of violence are as detailed and can provide comprehensive reports about the violence they have witnessed.

It was predicted that repeated questioning would lead to more details reported, a results that has been confirmed in previous research regarding childrens' report of sexual abuse (Leander, 2010). Contrary to this prediction, repeated questioning did not lead to more detailed reports. This finding is important, as it is inconsistent with previous research (Leander, 2010). There are several possible explanations for this finding. First, it is possible that the uneven distribution of children in the two groups had an effect on the results, as one of the groups contained 53 children and the other only 11 . Another explanation may be the way the data was coded. As only the total numbers of details for all interviews were coded, no conclusions can be drawn about the numbers of new and unique details for each interview. Future coding of similar type of data should therefore quantify the amount of details for each interview to better understand the report pattern of child witnesses. Further research should also more closely investigate, not only if children provide more information about events they have experienced in follow-up interviews, but also on how information can be affected by multiple interviews.

Previous research has pointed out several reasons, both cognitive and emotional, to why it is beneficial to conduct more than one interview with a child witness (La Rooy, et al., 2010). Studies has for example indicated that maltreated and abused children may need time to build rapport to dare report sensitive information (Leander, 2010). Since the children in the present study, contrary to sexually abused children, were very detailed in their initial interview and provided great amount of details at the very beginning, it could have been that there was little to be told in subsequent interviews, causing a ceiling effect. Repeated interviews could therefore be more efficient for other types of abuse, for example sexual abuse, where there is a low degree of disclosure initially in the first interview.

\section{Conclusions}

The present study was unique in several ways. The findings have implications for research related to childrens' memories and report of traumatic experiences, as well as practical implication for future treatment and evaluation of childrens' testimonies, and for the study of trauma and memory in children in general. The present results parallel and extend the findings of existing research about childrens' memories and report from witnessing violence. Most importantly they point to the importance of talking with children who have had experiences of witnessing violence, a result that has been confirmed in several previous studies (Eriksson, 2009; Steeves, Laughon, Parker \& Weierbach, 2007; Weinehall, 1997). There are several reasons as to why it is of great importance to interview these children about their experiences. One essential reason is that in a number of violent situations, that result in homicide (for example violence against women), the child and perpetrator are the only witnesses. If other evidence is missing, the child's testimony can play an important role in the criminal investigation. The results in the present study show that the reports of the children, due to 
their detailed descriptions of the violent episode, could very well work as evidence in criminal investigations.

Since a vast number of studies (for example Edleson, 1999; Överlien, 2010) have shown a positive link between witnessing violence and different types of external and internal problems, many of the children are in need of professional help. Intervention most often depends on the childrens' testimonies and disclosure, and by talking to these children about what they have witnessed, they will receive proper treatment and can be protected from being subjected to longer or repeated abuse. Children need to get their experiences recognized and affirmed as well as validated. For them to not become invisible victims it is of great importance to let the violence they have witnessed be a topic of conversation. Talking about the violence, whether it takes place in a police interrogation, within a therapeutic context or in conversation with a family member or beloved one, will increase the child's chances to interpret and make sense of his or her experiences.

\section{References}

Arata, C. B. (1994). Examining questionable child sexual abuse allegations in their environmental and psychodynamic contexts. Journal of Child Sexual Abuse, 3, 21-33.

Bahrick, L. E., Parker, J. F., Fivush, R., \& Levitt, M. (1998). The effects of stress on young childrens' memory of a natural disaster. Journal of Experimental Psychology: Applied, 4, 308-331.

Bartko, J. J. (1966). The intraclass correlation coefficient as a measure of reliability. Psychological Reports, 19, 3-11.

Brottförebyggandet rådet (Brå). (2008). Brottsutvecklingen i Sverige fram till år 2007. [Crime development in Sweden up to 2007]. Rapport 2008:23. Stockholm: Fritzes.

Brottförebyggandet rådet (Brå). (2007). Utvecklingen av dödligt våld mot kvinnor i nära relationer. [The development of deadly violence against women in close relationships]. Rapport 2007:6. Stockholm: Fritzes.

Burman, S., \& Allen-Meares, P. (1994). Neglected victims of murder: childrens' witness to parental homicide. Social Work, 39, 28-34.

Christianson, S-Å. (1992). Emotional stress and eyewitness memory: A critical review. Psychological Bulletin, $112,238-246$.

Christianson, S.-Å., Azad, A., Leander, L., \& Selenius, H. (manuscript in preparation). Children as witnesses to homicidal violence: what they remember and tell. Manuskript i föreberedelse.

Deffenbacher, K. A., Bornstein, B. H., Penrod, S. D., \& McGorty, E. K. (2004). A meta-analytic review of the effects of high stress on eyewitness memory. Law \& Human Behavior, 28, 687-706.

Edleson, J. L. (1999). Childrens' witnessing of adult domestic violence. Journal of Interpersonal Violence, 14, 838-870.

Eisen, M., Qin, J. J., Goodman, G. S., \& Davis, S. (2002). Memory and suggestibility in maltreated children; Age, stress, arousal, dissociation, and psychopathology. Journal of Experimental Child Psychology, 83, 176-212.

Eriksson, M., Biller, H., \& Balkmar, D. (2006). Mäns våldsutövande - barns upplevelser. [Men’s violence childrens' experiences]. Rapport Stockholm: Fritzes.

Eriksson, M., Källström Cater, Å., Dahlkild-Öhman, G., \& Näsman, E. (2008). Barns röster om våld. Att tolka och förstå. [Childrens' report of violence. Interoperation and understanding]. Rapport Malmö: Gleerups.

Eth, S., \& Pynoos, R. S. (1994). Children who witness the homicide of a parent. Psychiatry: Interpersonal and Biological Processes, 57, 287-306.

Farrar, M. J., \& Goodman, G. S. (1992). Developmental changes in event memory. Child Development, 63, 173187.

Finkelhor, D., Ormod, R. K., \& Turner, H. A. (2007). Polyvictimization: A neglected component in child victimization. Child Abuse \& Neglect, 31, 7-16.

Fivush, R., Sales, J. M., Goldberg, A., Bahrick, L., \& Parker, J. (2004). Weathering the storm: childrens' longterm recall of hurricane Andrew. Memory, 12, 104-118.

Follmer Greenhoot, A., McCloskey, L., \& Glisky, E. (2005). A longitudinal study of adolescents' recollections of family violence. Applied Cognitive Psychology, 19, 719-743. 
Fowler, P. J., Tompsett, C. J., Braciszewski, J. M., Jacques-Tiura, A. J., \& Baltes, B. B. (2009). Community violence: A meta-analysis on the effect of exposure and mental outcomes of children and adolescent. Development and Psychopathology, 21, 227-259.

FUK (17§) 2001:645, Förundersökningskungörelsen. [The Pre-trial Order].

Ghetti, S., Goodman, G. S., Eisen, M. L., Qin, J., \& Davis, S. L. (2002). Consistency in childrens' reports of sexual and physical abuse. Child Abuse \& Neglect, 26, 977-995.

Goodman, G. S., Hirschman, J. E., Hepps, D. H., \& Rudy, L. (1991). Childrens' memory for stressful events. Merril Palmer Quarterly, 37, 109-158.

Goodman, G.A., Quas, J.A., Batterman-Faunce, J. M., Riddlesberger, M. M., \& Kuhn, J. (1994). Predictors of accurate and inaccurate memories of traumatic events experienced in childhood. Consciousness and Cognition, 3, 269-294.

Goodman, G.A., Quas, J.A., Batterman-Faunce, J. M., Riddlesberger, M. M., \& Kuhn, J. (1997). Childrens' reactions to and memory for a stressful event: Influence of age, anatomical dolls, knowledge and parental attachment. Applied Developmental Science, 1, 54-75.

Goodman, G.A., \& Quas, J.A. (2008). Repeated interviews and childrens' memory: It's more than just how many. Current Direction in Psychological Science, 17, 386-390.

Hershkowitz, I., Lanes, O., \& Lamb, M. E. (2007). Exploring the disclosure of child sexual abuse with alleged victims and their parents. Child Abuse \& Neglect, 31, 111-123.

Hershkowitz, I., \& Terner, A. (2007). The effects of repeated interviewing on childrens' forensic statements of sexual abuse. Applied Cognitive Psychology, 21, 1131-1143.

Hintzman, D. L. (1986). "Schema abstraction" in a multiple-trace memory model. Psychological review, 93, 411-428.

Howe, M. L., Courage, M. L., \& Peterson, C. (1996). How can I remember when "I" wasn't there: Long-term retention of traumatic experiences and emergence of the cognitive self. In K. Pezdek, \& W. W. P. Banks (Eds.). The recovered memory/false memory debate. (pp. 121-149). San Diego, CA, US: Academic Press.

Hudson, J. A. (1990). Constructive processing in childrens' event memory. Developmental Psychology, 26, 180187.

Hudson, J. A., Fivush, R., \& Kuebli, J. (1992). Scripts and episodes: the development of event memory. Applied Cognitive Psychology, 6, 483-505.

Janosz, M., Archambault, I., Pagani, L. S., Pascal, S., Morin, A. J. S., \& Bowen, F. (2008). Are there detrimental effects of witnessing school violence in early adolescence? Journal of Adolescent Health, 43, 600-608.

La Rooy, D., Katz, C., Malloy, L. C., \& Lamb, M. E. (2010). Do we need to rethink guidance on repeated interviews? Psychology, Public Policy, and Law, 16, 373-392.

La Rooy, D., Lamb, M. E., \& Pipe, M. E. (2009). Repeated interviewing: A critical evaluation of the risks and potential benefits. In K. Kuehnle \& M. Connell (Eds.). The Evaluation of Child Sexual Abuse Allegations: A Comprehensive Guide to Assessment and Testimony (pp. 327-361). Hoboken, NJ: Wiley.

Leander, L. (2010). Police interviews with child sexual abuse victims: Patterns of reporting, avoidance and denial. Child Abuse \& Neglect, 34, 192-205.

Leander, L., Granhag, P.A., \& Christianson, S. Å., (2005). Children exposed to obscene phone calls: What they remember and tell. Child Abuse \& Neglect, 29, 871-888.

Leander, L., Christianson, S. Å., \& Granhag, P. A. (2007). A sexual abuse case study: Childrens' memories and reports. Psychiatry, Psychology and Law, 14, 120-129.

London, K., Bruck, M., Ceci, S. J., \& Shuman, D. W. (2007). Disclosure of child sexual abuse: A review of the contemporary empirical literature. In M.-E. Pipe, M. E. Lamb, Y. Orbach, A.-C. Cederborg (Eds.), Child sexual abuse: Disclosure, delay and denial (pp. 11-37). New Jersey: Lawrence Erbaum Associates, Publishers.

Lyckner, B. (1997). "Jag var jätterädd när pappa slog mamma”. Förskolebarn berättar. ["I was really afraid when dad hit mom." Preschool childrens' reports]. Rapport 1997:02. Stockholm: Omsorgsnämnden.

Powell, M.B., Roberts, K. P., Ceci, S.J., \& Hembrooke, H.H. (1999). The effects of repeated experience on childrens' suggestibility. Developmental Psychology, 35, 1462-1477.

Putnam, F. W. (1997). Dissociation in children and adolescents: A developmental perspective. New York: Guilford.

Pynoos, R. S., \& Eth, S. (1985). Children traumatized by witnessing acts of personal violence: homicide, rape or suicide behavior. In S. Eth, \& R. S. Pynoos, (Eds.). Post-traumatic stress disorder in children. (pp. 1744). Washington, DC: American Psychiatric Press.

Pynoos, R. S., \& Eth, S. (1984). The child as witness to homicide. Journal of Social Issues, 40, 87-108.

Roberts, K.P., \& Powell, M.B. (2001). Describing individual incidents of sexual abuse: A review of research on the effects of multiple sources of information on childrens' reports. Child Abuse \& Neglect, 25, 16431659 . 
Schank, R. \& Abelson, R. (1977). Scripts, plans, goals and understanding. An inquiry into human knowledge structures. Hillsdal: Erlbaum.

Sjöberg, R., \& Lindblad, F. (2002). Limited disclosure of sexual abuse in children whose experiences were documented by videotape. American Journal of Psychiatry, 158, 312-314.

Smith, P. H., Morroco, K. E., \& Butts, J. D. (1998). Partner homicide in context: a population-based perspective. Homicide Studies, 26, 400-421.

Steeves, R., Laughon, K., Parker, B., \& Weierbach, F. (2007). Talking about talk: the experiences of boys who survived intraparental homicide. Issues in Mental Health Nursing, 28, 899-912.

Strati, K. (2010). "Peek-a-boo. How can you be there? Analytic work with a severely traumatized two-and-ahalf-year-old girl. Journal of Child Psychotherapy, 36, 16.32.

Svedin, C.G., \& Back, M. (2003). Varför berättar de inte: Om att utnyttjas i barnpornografi. [Why don`t they tell?: Being used in child pornography]. Falun: Rädda Barnen.

Terr, L. (1991). Acute responses to external events and posttraumatic stress disorder. In M. Lewis (Ed.), Child and adolescent psychiatry: A comprehensive textbook (pp. 755-763). Baltimore, MD: Williams \& Wilkins Co.

Terr, L. (1988). What happens to early memories of trauma? A study of twenty children under age five at the time of documented traumatic events. Journal of the American Academy of Child \& Adolescent Psychiatry, 27, $96-104$.

Weinehall, K. (1997). Att växa upp i våldets närhet. [Growing up in the presence of violence]. Umeå universitet: Pedagogiska Institutionen.

Weist, M. D., Acosta, O. M., \& Youngstrom, E. A. (2001). Predictors of violence exposure among inner-city youth. Journal of Clinical Child Psychology, 30, 187-198.

Överlien, C. (2010). Children exposed to domestic violence: Conclusions from the literature and challenges ahead. Journal of Social Work, 10, 80-97.

Överlien, C. \& Hydén, M. (2007) Att tvingas lyssna. Hur barn bevittnar pappas våld mot mamma. [Being forced to listen. How children witness their fathers' violence against their mother]. Barn, 1, 9-25. 


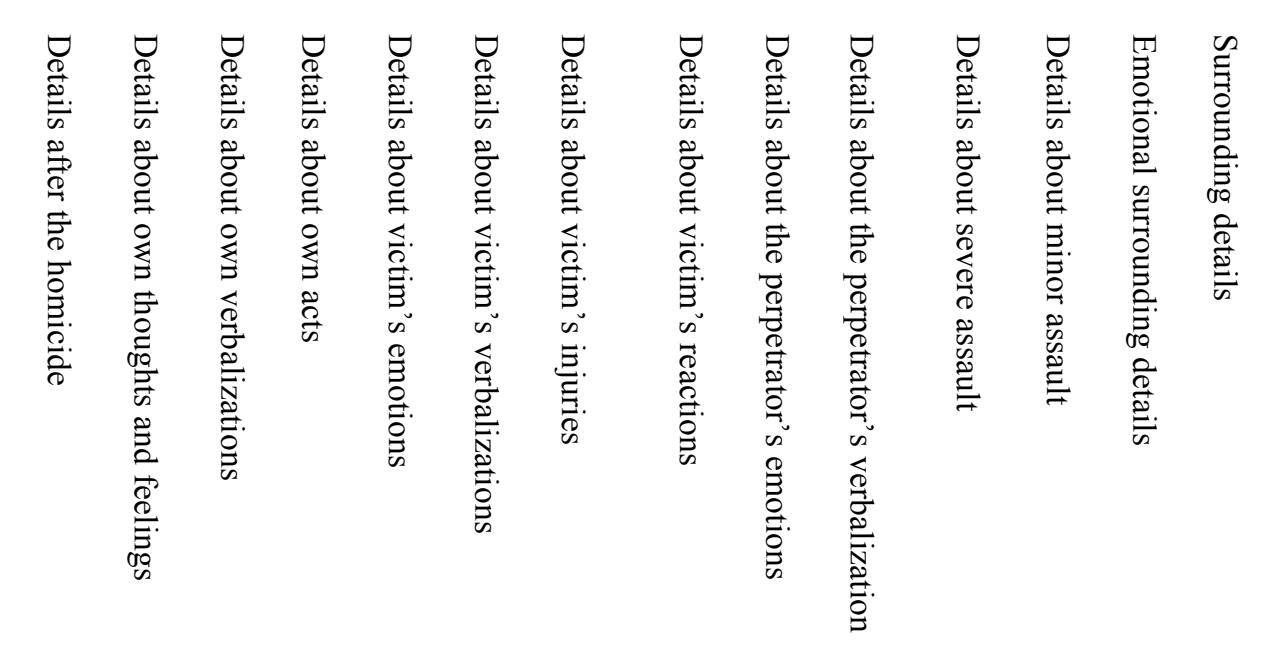

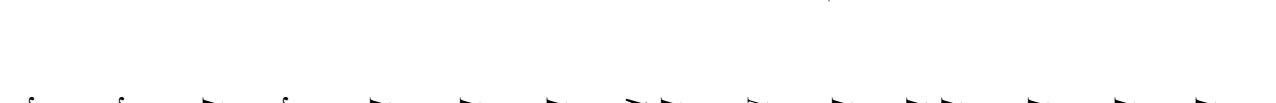

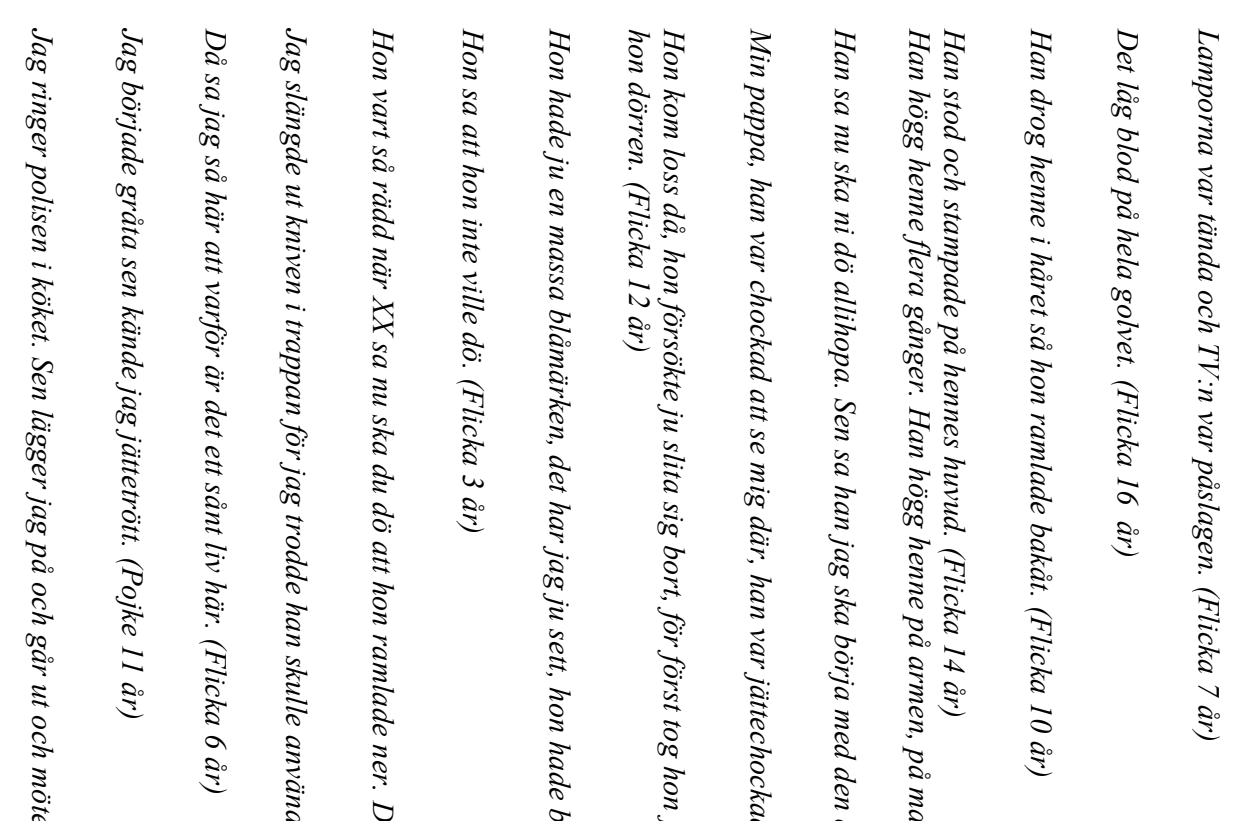

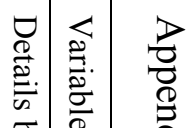

家

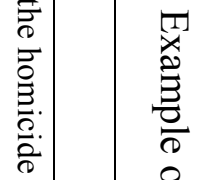

